\title{
FILOSOFIA E PSICANÁLISE
}

Custódio Luís S. de Almeida*

Anamnese - a filosofia e o retorno do reprimido, do professor Ernildo Stein, é um conjunto de doze ensaios, publicados em 1997 pela Editora da PUCRs, que nos brinda com temas da relação Filosofia-Psicanálise, numa linguagem polêmica, associada a um estilo literário e livre. Sendo um livro de ensaios, não há exigência de uma leitura seqüenciada, nem de conhecimento profundo de filosofia e psicanálise, mas, com certeza, o leitor será naturalmente lançado num campo muito fértil, cujas trilhas de discussão e as notáveis elaborações construídas são um convite ao estudo dos temas e problemas tratados.

Chama à atenção o fato de o autor estar mais empenhado no incremento do debate que se abre entre Psicanálise e Filosofia do que na superação dos problemas nascidos desta relação. Esta posição é deveras sugestiva, pois Stein nos mostra que levar a sério os problemas teóricos no campo da filosofia é, primeiro, esclarecê-los, retirando-os do terreno da jogatina e da ambigüidade, que lança a discussão na falácia e, segundo, abdicar das soluções meramente retóricas quando a pesquisa ainda não se fizer suficiente para apresentar respostas seguras e significativas. Stein não assume aqui uma atitude romântica e muito menos messiânica, dando respostas definitivas aos conflitos gerados; pelo contrário, através de uma analítica fenomenológico-existencial dos conflitos e de seus temas geradores, ele esclarece conceitos, localiza problemas e abre um espaço público de debate.

Se tomamos como eixo a questão do dualismo na Psicanálise, encontraremos muitas dúvidas e diversas críticas já formuladas com relação ao conflito dicotômico dos pares de conceito: mente-corpo, consciente-inconsciente, sentido-pulsão, energética-hermenêutica, etc. A utilização destes conceitos, à primeira vista, atesta o dualismo, dando espaço para a constatação de uma fraqueza teórica intransponivel. Por quê? Porque o dualismo explicita os impasses e a ambigüidade das teorias, à medida que as discussões são suspensas diante de "argumentos" autoritários, que recorrendo ao "estranho" e ao "desconhecido" justificam suas afirmações, mas a análise do autor é contundente ao mostrar que a fraqueza teórica de qualquer dualismo não se encontra, aprioristicamente, no fato de sua exis-

* Professor da Universidade Federal do Ceará, UFCE; doutorando em Filosofia na Pontifícia Universidade Católica do RS, PUCRS. 
tência e muito menos é resolvida pelas estratégias de encobrimento. O dualismo é pernicioso ao conhecimento quando é escamoteado e não enfrentado e, principalmente, quando é utilizado como resposta à questões ainda carentes de estudos e pesquisas. Stein parece sugerir uma "terceira margem", de onde se possa viabilizar uma analítica do problema, sem sucumbir à força da ideologia que se apropria do saber para manipulação do conhecimento. Mas, este não é um lugar de conciliação, ao contrário, é um lugar onde a tensão aparece claramente sem que se necessite escondê-la ou eliminá-la. Aqui o objetivo não é fornecer soluções aos conflitos teónicos e existenciais e muito menos ofertar o paraíso aos aflitos, mas importa viver o acontecer do mundo e experimentar o fenômeno de estar-aí, lançado na mundanidade e suspenso no tempo. É muito interessante notar como, com sutileza, Stein lança mão da "ontologia fundamental" e do método analíticoexistencial de Heidegger para dialogar com a Psicanálise, sugerindo, neste sentido uma poderosa construção teórica para o desvelamento dos conflitos.

É possível identificar três diferentes modos de análise dos temas e problemas tratados neste livro: 1) O modo epistemológico, ressaltado nos ensaios: - a questão mente-corpo na psicanálise; - psicanálise e universidade, partenogênese do saber e delírio de autonomia; - psicopatologia e pesquisa psicanalítica; - referências para a psicanálise: paradigmas ordenadores e paradigmas instauradores; 2) 0 modo metodológico, destacado nos ensaios: - fundamentos analítico-existenciais da psicanálise: um estudo da melancolia; - the waste land e a repetição na psicanálise: resto, sintoma e repetição; - o estranho numa tradução: o múltiplo interesse na psicanálise; 3) o pressuposto ontológico, legivel nas entrelinhas de todo o texto e explícito nos ensaios: - Lacan e Heidegger: dois intérpretes, - Grande sertão: veredas, verdade e método (o estranho e o familiar). Não quero com esta divisão fazer cortes indevidos, mas mostrar como o autor construiu um rico material de debate, voltado para a clareza do texto e para esclarecimento dos conceitos, na tentativa de fornecer um estatuto teórico para o conhecimento psicanalítico.

O modo epistemológico de análise é introduzido com a questão "como a epistemologia serve ao saber?". Inicialmente, o autor define o que é epistemologia, pois se tem "abusado" muito do termo. "Epistemologia é filosofia" e, conseqüentemente, "não é o lugar do saber" e "não é o lugar do poder", mas é um instrumental para questionar, problematizar e apontar soluções aos problemas que se colocam nas várias esferas do saber. Porque a epistemologia pensa as condições de possibilidade do discurso da ciência, ela é um saber metaempírico que conhece os limites da ciência, o seu falibilismo e os perigos de universalizações indevidas. Por isso, "a explosão da epistemologia nos revela a crise do saber científico e do poder".

Na discussão epistemológica dos ensaios, o autor põe em evidência a crise do saber sistemático, organizado, prognosticador e universalizante e, mais que isso, tem a intenção de mostrar que o dualismo trazido pela psicanálise entre mentecorpo, sentido-pulsão, sentido-força não encontrará solução ou saída no âmbito da epistemologia, pois a unidade para a qual a psicanálise aponta o fim deste dualis- 
mo é o inconsciente; uma "instância" para além da circunscrição das epistemologias, um lugar hermenêutico.

Se por um lado a explosão da epistemologia é um sintoma da crise do saber e do poder do saber, por outro lado, é uma evidência da "historicidade do saber e o sem sentido das propostas que falam em necessidade absoluta e contingência absoluta". Seria como se a epistemologia estivesse contribuindo para afirmar no próprio espaço acadêmico os limites da consciência e, por isso mesmo, apontasse para o Outro, o Estranho, o Sinistro.

A questão agora é: qual a possibilidade do conhecimento na psicanálise? Como articular a questão mente-corpo apesar dos impasses epistemológicos que ela traz? A epistemologia implode ao tentar resolver esse dualismo porque está viciada em critérios, classificações, diferenciações, ordenamentos; estando presa na sua própria teia. Na psicanálise o problema é transposto para a forma forçasentido, como duas dimensões irredutíveis. Acontece aqui a passagem de um modo de pensar classificatório para um modo hermenêutico. Em que consiste esta passagem? Poderiamos lembrar de Hermes com sua vara mágica, assumindo a tarefa de traduzir para os homens os oráculos de Zeus. A passagem feita pela psicanálise da esfera estritamente epistemológica para o lugar hermenêutico corresponde à travessia feita através de dois territórios qualitativamente diferentes. No caso de Hermes, traduzir do divino para o humano é transpor uma barreira intransponível, em que não há sinonímia capaz de realizá-la; dizer aos homens a vontade dos deuses é como transformar o divino em humano; para fazer isso só podemos pensar em aproximações hermenêuticas:

Podemos dizer com o autor que é este o dilema da psicanálise: "Nas relações entre o sentido manifesto e o conteúdo latente coloca-se o problema do difícil trânsito entre força e sentido, entre pulsão e expressão, entre energia e compreensão (sentido e causalidade)". A psicanálise trabalha com categorias dicotômicas e somente na hermenêutica seria possivel operar com elas. Mas mesmo assim fica a pergunta: "como conciliar energética e hermenêutica no conhecimento psicanalítico?" A resposta possível não é reduzir uma esfera à outra, portanto, não é transformar a pulsão em sentido, nem o contrário - isso seria como reduzir o empírico ao transcendental ou o transcendental ao empírico - mas sim encontrar uma instância, uma unidade geradora das duas esferas: 0 inconsciente? Mas não basta, por se só o inconsciente não nos diz nada. É preciso encontrar uma manifestação do inconsciente que seja um "centro para onde converge a pulsão e de onde emana o sentido": o desejo?

$O$ ensaio Psicanálise e universidade: partenogênese do saber e delírio de autonomia retrata de forma magnífica os conflitos da relação filosofia-ciência e psicanálise. O tema tratado aqui é uma demarcação de fronteiras entre dois tipos de discurso: o acadêmico e o psicanalítico. $O$ professor Stein cede à tentação e faz uma espécie de jogo para apresentar a relação entre a universidade e a psicanálise, e joga de forma notável. O convite ao jogo nos leva à "outra cena", diferente da cena pública em que estamos acostumados a atuar como sujeitos que representam as coisas e se representam a si mesmos. Assim, a Psicanálise remeteria à partenogênese e universidade teria a ver com autonomia. Stein continua jogando e 
relaciona partenogênese com delírio e autonomia com saber, essas são palavraspeça do jogo. Podemos notar também que o título do livro Anamnese: a filosofia e o retorno do reprimido é o resultado parcial do jogo; jogo inacabado, portanto, sem vencedores.

Metodologicamente, Stein se dedica a situar o estilo do discurso psicanalítico e diferenciá-lo daqueles discursos que estão preocupados em dar conta, dedutivamente, de seus campos e objetos de estudo. A partir desta intenção, ele aproveita para fornecer pistas filosóficas para a Psicanálise, isto é, aqueles modos de fazer filosofia que, em vez de apontar para a verdade última, eliminando a tensão entre finitude e infinitude, transcendental e empírico, contingência e necessidade, estão mais preocupados em deixar a falta, o oculto, como lugar irredutível de criação do novo.

Há uma tendência intelectual que sempre elege um texto canônico, uma "gramática divina", a partir de onde se uniformiza a leitura de qualquer tradição; como se este texto eleito fosse a fonte originária capaz de tornar claros os discursos e de fornecer todo instrumental teórico necessário para a certa compreensão de todas as leituras. Esta seria uma tendência tradicional e hegemônica. O pressuposto dos textos canônicos e a regra magna das "gramáticas divinas" é que o significado verdadeiro das coisas é encontrado na linguagem, via enunciados proposicionais que vão significando mais à medida que um universo conceitual vai sendo definido e passa a legitimar as proposições particulares. $O$ acesso aos objetos é um acesso mediado lingüisticamente e obedece às regras da linguagem. $\mathrm{O}$ significado vem à tona através dos enunciados bem construidos e esse padrão é apresentado como aquele que é necessário para a leitura dos fenômenos da natureza, do mundo e da alma.

O autor mostra que o estudo dos textos psicanalíticos contraria a lógica e as regras da "gramática divina", sobretudo os textos freudianos, nos quais as proposições particulares estão, via de regra, autonomizadas, portanto, independentes de um universo conceitual; isso transpõe o lugar do significado, muitas vezes, das frases enunciativas para as palavras (isoladas), e isso é delirante. Nasce, neste contexto, a pergunta pela cientificidade da psicanálise; como é possivel método, organização e sistematicidade, que são marcas constitutivas do saber científico, em "um discurso que toma como núcleo central não propriamente as sentenças, mas conceitos fundamentais isoladamente"?

O discurso e o "método" psicanalíticos rompem com a gramática tradicional e instauram uma nova forma de compreensão, baseada no significante, trazem equivocos mais do que esclarecimentos e abrem um espaço especulativo fantástico, pois se as palavras isoladas das sentenças não significam nada ou são vazias, como, então, transferir exatamente para este lugar vazio a significatividade mais "profunda" do mundo e dos fenômenos psíquicos? Parece que neste lugar os caminhos hermenêutico e especulativo "embaçam" a estrada epistemológica, tornando-a extremamente perigosa e "passamos de alguma maneira a nos apossar, muito mais proximamente, daquilo que é propriamente o objeto de estudo da psicanálise". 
Aqui temos, segundo Stein, que enfrentar a produção de ambigüidades. Se a distância que a psicanálise tenta "obturar" entre nós e os objetos fosse possivel sem discurso, provavelmente a ambigüidade estaria eliminada, mas isso só aconteceria através de uma visão mística, translingüística. Como o discurso permanece apesar da tentativa de fazer a coisa mesma se manifestar, então não há saída. Há uma grande aproximação trazida pela "obturação" feita: não é mais o significado que manifesta o sentido autêntico das coisas, mas o significante; no entanto, mesmo o significante não prescinde do discurso para vir à tona e qualquer discurso é, ao mesmo tempo, apofântico e hermenêutico, portanto, lugar de ambigüidades. Stein pontua que, no caso da psicanálise, a coincidência das leituras dos pesquisadores sobre seu objeto "é quase impossível" e o "quase" aqui é um mero atenuante. Daí não ser possivel uma última leitura em psicanálise: há sempre uma leitura puxando outra, uma leitura que contesta a outra, tonando a teia sempre inacabada.

Haveria, pois, metodologicamente, dois universos paradigmáticos: o ordenador e o instaurador. Se por um lado os paradigmas ordenadores buscam instalar comunidades de pesquisa através de teorias bem definidas e testáveis intersubjetivamente e, também, comunidades de comunicação através do estabelecimento de regras lógicas para o discurso; os paradigmas instauradores, por outro lado, não estão tão interessados na verdade ou falsidade das proposições, querem mais preservar a continuidade do discurso e não seu fechamento, por isso, pode-se dizer que "paradigmas instauradores não erram, paradigmas instauradores não fracassam", pois eles têm um universo semântico próprio.

Há, nessa perspectiva, o rompimento da psicanálise com a idéia ordenadora de que 0 "conhecimento se produz através da racionalidade". Por quê? Porque a psicanálise "se liga a uma espécie de pragmática, uma relação entre o sujeito e o uso que ele faz do signo, o uso que faz do significante". É aí que se faz a clivagem do conceito de verdade. "Não é apenas a verdade de uma proposição, numa frase, mas é a verdade de um modo de inclinação da relação do enunciador na sua articulação com o significante". "Os significantes são carregados de algo que os fazia perdidos numa lógica do discurso comum que produz verdade e falsidade", por isso, a psicanálise é sempre uma crítica ao universo da lógica e "é um enigma para o discurso lógico semântico". Mas, que saídas a psicanálise encontra para transitar no mundo científico? Sabe-se, pelo menos, que o texto psicanalítico deve ser aberto, inacabado, uma contínua tarefa, um ensaio.

Finalmente, podemos dizer que tanto o modo epistemológico quanto o modo metodológico de análise utilizados nesse livro têm seus pressupostos na ontologia fundamental de Martin Heidegger. A palavra-chave para se compreender esse pensamento é "finitude". A desconstrução fenomenológica feita por Heidegger na tradição filosófica ocidental significou uma travessia da história em busca do "originário" encoberto pelo tempo. Este processo analítico-existencial desmascarou as objetivações do Absoluto, do Infinito e do Eterno, chegando às formas ontológicas elementares da existência: historicidade, finitude e temporalidade. Desta forma, o Outro, o Estranho, o Desconhecido, passaram a ser, também, marcas onginárias 
da existência tanto quanto o Eu, o Familiar, o Conhecido e não mais lugares inexistentes ou abandonados pela razão.

Heidegger desloca a finitude negada para o centro da cena e com ela chama atenção para o des-conhecido. $O$ homem se dá conta que não pode ollhar de fora de si mesmo. Existindo no modo de ser da historicidade, ele deixa de ser o senhor que tem tudo sob seu controle, perde seu poder infinito e é lançado na finitude. Sem resposta às questões fundamentais da existência humana e sendo, constitutivamente, um ser-para-a-morte, o ser humano é lançado no mar do desconhecido e se reconhece como ilha.

Através da análise da existência humana, enquanto existência temporal "no mundo, do mundo e com o mundo", Heidegger vai afirmar a sua dimensão finita e negadora. O homem é uma permanente construção; é projeto para o futuro, mas sempre nos limites do seu "mundo"; é um ser que planeja porque sabe que não está pronto. Qualquer projeto nega o familiar e revela a saudade do estranho. Tarefa sempre inacabada, o homem sempre está diante de múltiplas possibilidades; ele é o não-Ser, "seu verdadeiro ser consiste em objetivar aquilo que ainda não é". É a descoberta da finitude humana que revela a infinitude do Ser, sua determinidade revela a indeterminidade do Ser. Sem poder se despregar do "mundo", o "eu" se despe da condição de senhor da história e isso faz da ontologia fundamental de Heidegger um pensamento para além de qualquer filosofia da subjetividade. Não por acaso Stein dá o título: Lacan e Heidegger - dois intérpretes, a um dos ensaios, mostrando que os dois intérpretes, respectivamente de Freud e Kant, produziram um plus que leva adiante o pensamento ocidental; não se restringindo a suas respectivas áreas de conhecimento, mas, principalmente, proporcionando uma relação interativa entre ambas e sacando da filosofia a inspiração ontológica.

Este livro é mais do que o fruto da seriedade e rigor teórico com que o filósofo produz suas obras, mas a ele se soma uma riquissima experiência de passagem pelo divã e pelo exercício da clínica. A matriz central de pensamento e a multiplicidade dos conflitos gerados desta união o tornam um presente e um convite para aqueles que, abertos ao diálogo, não têm dúvida de que a filosofia é uma atividade humana e, por isso, estritamente mundana, sendo capaz de transitar nas entranhas do psiquismo. 